\title{
Optimal pH strategy for hypothermic circulatory arrest
}

Richard A. Jonas, MD

From Children's Hospital (Cardiovascular Surgeon-in-Chief) and Harvard Medical School (William E. Ladd Professor of Surgery), Boston, Mass.

Received for publication Aug 11, 2000; accepted for publication Aug 22, 2000.

Address for reprints: Richard Jonas, MD, Department of Cardiac Surgery, Children's Hospital, 300 Longwood Ave, Boston, MA 02115 .

J Thorac Cardiovasc Surg 2003;125:S39-40

Originally published in J Thorac Cardiovasc Surg 2001;121:204-5.

Copyright $\odot 2003$ by The American Association for Thoracic Surgery

$0022-5223 / 2003 \$ 30.00+0$

doi: $10.1067 / \mathrm{mtc} .2003 .220$

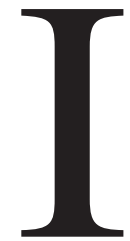

$\mathrm{t}$ was several years after the beginning of open heart surgery before hypothermia was introduced as a component of cardiopulmonary bypass (CPB). At about this time in the late 1950s, blood gas analysis became more readily available and revealed a surprising fact: when blood is cooled by the heat exchanger in the circuit, $\mathrm{pH}$ changes in an alkaline direction. The usual response in the 1960s and 1970s was to compensate for this alkaline shift by adding carbon dioxide, a technique that has come to be known as the pH-stat strategy. This also had what was perceived to be an important advantage in that carbon dioxide is a potent cerebral vasodilator. It was believed that adding carbon dioxide would increase the safety margin for cerebral oxygen supply and reduce the risk of major neurologic injury, which was all too common in the early years of CPB.

In the late 1970s and early 1980s, a number of reports appeared that questioned whether the $\mathrm{pH}$-stat strategy was indeed the correct response to the alkaline shift with hypothermia. It was found that cold-blooded vertebrates simply allow their blood $\mathrm{pH}$ to drift in an alkaline direction. It appeared that this alpha-stat strategy optimized intracellular enzyme function. Studies in dogs showed that the threshold for ventricular fibrillation was lower with the more acidotic $\mathrm{pH}$-stat strategy. It also became increasingly apparent that the most common cause of neurologic injury in adults was embolic stroke rather than the global hypoxic insults that had been more common in the early years of bypass. Even if there was not a definite stroke, psychologists could measure important deficits in cognitive function in a remarkably high percentage of adult patients after heart surgery. Microembolization of atherosclerotic debris, fat, and air was probably the cause. It followed that if cerebral blood flow was increased to excessive, "luxuriant" levels by adding carbon dioxide, then injury would be increased. Randomized trials of neuropsychometric outcome have confirmed just this. Three of four trials demonstrated an improved cognitive outcome in adults undergoing continuous mildly or moderately hypothermic CPB with the alpha-stat strategy relative to the $\mathrm{pH}$-stat strategy.

The shift in $\mathrm{pH}$ strategy from $\mathrm{pH}$-stat to alpha-stat was applied just as enthusiastically to children as adults in the early 1980s, although there was little evidence to support macroembolization or microembolization as important mechanisms of injury in this population. Apart from their lack of atherosclerotic vessels and calcified valves, in contrast to adults, children have intracardiac problems that require exposure through small incisions. Blood returning to the heart impairs exposure and can result in less accurate repair. This collateral return is almost always increased in patients who have cyanotic conditions and steals an important proportion of blood from the systemic circulation. A common response of surgical teams is to reduce flow and temperature or to apply deep hypothermic circulatory arrest (DHCA). Is a pH strategy that reduces cerebral blood flow the appropriate one under such circumstances? The article by Priestley and associates ${ }^{1}$ in this issue of the Journal is further evidence that the alpha-stat strategy results in a greater degree of cerebral injury when DHCA is used.

Priestley and colleagues ${ }^{1}$ subjected 5- to 10-day-old piglets to 90 minutes of DHCA at a brain temperature of $20^{\circ} \mathrm{C}$. Animals were hemodiluted to a hematocrit value of $20 \%$ to $25 \%$ and were cooled at a flow rate of $100 \mathrm{~mL} \times \mathrm{kg}^{-1} \times \mathrm{min}^{-1}$. After being rewarmed, the animals were taken off $\mathrm{CPB}$ and were allowed to survive for the next 48 hours. They were assessed for neurologic injury by means of a graded scoring system by a blinded observer. Brain histologic features were also 
assessed by a blinded observer. The authors found a dramatic difference between the 2 groups. At 48 hours only 1 of 7 piglets that underwent the $\mathrm{pH}$-stat strategy had measurable impairment, whereas in the alpha-stat group 1 piglet had died, 1 had moderate disability, and 3 had mild disability. Histologic injury was also greater in the alpha-stat group.

This report by Priestley and coworkers is an important addition to the evidence supporting the advantages of the $\mathrm{pH}$-stat strategy for DHCA. It is the first laboratory survival study to study $\mathrm{pH}$ strategy with both behavioral and histologic end points. Two previous reports of short-term laboratory studies from our group suggested that the alpha-stat strategy limited cerebral oxygen delivery before circulatory arrest. ${ }^{2,3}$ We speculated that this would increase the risk of injury, as Priestley and colleagues have demonstrated. Another important report from the Duke group, who have a longstanding interest in cerebral injury associated with $\mathrm{CPB}$, emphasizes that the alpha-stat strategy is particularly likely to be injurious in the setting of increased collateral steal to the lungs. ${ }^{4}$ The more alkaline $\mathrm{pH}$ of alpha-stat reduces pulmonary resistance and increases cerebral resistance, thereby increasing the steal from the cerebral to the pulmonary circulation. In clinical practice, the increased left heart return is likely to result in the surgical team requesting a lower perfusion flow rate. $\mathrm{We}^{5}$ have previously speculated that a virtual epidemic of choreoathetosis, which we saw in the late 1980s in patients with collateral-dependent pulmonary circulation after we changed to the alpha-stat strategy, resulted from this steal effect.

Only one randomized clinical trial of $\mathrm{pH}$ strategy has been conducted in a pediatric population, which our group reported in this Journal in 1997.6 Most of these patients did not have circulatory arrest, but they all were subjected to deep hypothermic CPB. Among the 182 infants in the study, all 4 deaths occurred in the alpha-stat group $(P=.058)$. In the largest and most homogeneous subgroup of patients, those with transposition $(\mathrm{n}=92)$, there was less postoperative acidosis $(P=.02)$, less hypotension $(P=.05)$, and shorter duration of ventilation and intensive care unit stay $(P=.01)$. Developmental follow-up of 93 children with cyanotic conditions, such as transposition and tetralogy, revealed approximately a 5-point higher outcome with the $\mathrm{pH}$-stat strategy, although this difference did not achieve significance. Interestingly, in the small subgroup of 16 patients with ventricular septal defect or complete atrioventricular canal (9 alpha-stat, 7 pH-stat), the alpha-stat group had a significantly higher score because of 2 outlier children with very low scores in the $\mathrm{pH}$-stat group.

It is important to remember that $\mathrm{pH}$ strategy is just one of the many manipulations undertaken during $\mathrm{CPB}$ that could limit oxygen delivery to the brain. Hemodilution to less than $30 \%$ to $35 \%$ has the potential to seriously limit oxygen delivery. The usual "full-flow" rate of $2.4 \mathrm{~L} \times \min ^{-1} \times$ $\mathrm{m}^{-2}$ used by most groups is a marginal "cardiac output." Collateral steal adds a further unknown. The impact of age is unclear. Are these data relevant to adults undergoing circulatory arrest? At present no single monitoring method is available to assure the cardiac operating room team that their system of CPB is delivering adequate oxygen to the brain during hypothermic bypass. Thus, it is critically important for more groups to undertake both laboratory studies like the study by Priestley's group, as well as clinical studies of developmental outcome, so that we can be sure we are adequately protecting the pediatric brain from neurologic injury during repair of congenital cardiac anomalies.

\section{References}

1. Priestley MA, Golden JA, O'Hara IB, McCann J, Kurth CD. Comparison of neurologic outcome after deep hypothermic circulatory arrest with alpha-stat and $\mathrm{pH}$-stat cardiopulmonary bypass in newborn pigs. J Thorac Cardiovasc Surg. 2001;121:336-43.

2. Aoki M, Nomura F, Stromski ME, Tsuji MK, Fackler JC, Hickey PR, et al. Effects of $\mathrm{pH}$ on brain energetics after hypothermic circulatory arrest. Ann Thorac Surg. 1993;55:1093-103.

3. Hiramatsu T, Miura T, Forbess JM, du Plessis AJ, Aoki M, Nomura $\mathrm{F}$, et al. $\mathrm{pH}$ strategies and cerebral energetics before and after circulatory arrest. J Thorac Cardiovasc Surg. 1995;109:948-58.

4. Kirshbom PM, Skaryak LR, DiBernardo LR, Kern FH, Greeley WJ, Gaynor JW, et al. pH-stat cooling improves cerebral metabolic recovery after circulatory arrest in a piglet model of aortopulmonary collaterals. J Thorac Cardiovasc Surg. 1996;111:147-57.

5. Wong PC, Barlow CF, Hickey PR, et al. Factors associated with choreoathetosis after cardiopulmonary bypass in children with congenital heart disease. Circulation. 1992;85(Suppl):II-18-26.

6. du Plessis AJ, Jonas RA, Wypij D, Hickey PR, Riviello J, Wessel DL, et al. Perioperative effects of alpha-stat versus $\mathrm{pH}$-stat strategies for deep hypothermic cardiopulmonary bypass in infants. $J$ Thorac Cardiovasc Surg. 1997;114:991-1001. 